\title{
Trans-Sphenoidal Surgery for "Growth Hormone- secreting adenoma; Revisiting Surgical Outcome
}

\author{
Bulent Ozdemir ${ }^{1(\mathbb{D})}$ Osman Ersegun Batcik ${ }^{1(\mathbb{I D})}$ \\ ${ }^{1}$ Department of Neurosurgery, Faculty of Medicine, Recep Tayyip Erdoğan University, Rize, Türkiye
}

Copyright@ Author(s) - Available online at https://dergipark.org.tr/en/pub/mbsjohs

Content of this journal is licensed under a Creative Commons Attribution-NonCommercial 4.0 International License,

\author{
Received: 07 junel 2021, Accepted: 21 August 2021, Published online: \\ (C) Ordu University Institute of Health Sciences, Turkey, 2021
}

\begin{abstract}
Objective: The purpose of this research is to review our clinical experience in transsphenoidal surgery for pituitary adenomas performed by Recep Tayyip Erdogan University Faculty of Medicine, Department of Neurosurgery and contribute to the literature in this way.

Methods: This is a case review of Growth Hormone secreting pituitary adenoma operated in the Recep Tayyip Erdogan University Faculty of Medicine Department of Neurosurgery from January 2014 to May 2021. All patients underwent a microscopic transnasal approach. It was aimed gross total excision of adenoma. For functioning adenomas, hormonal assessment was done on follow-up ( 8 weeks) and remission was said to be achieved if normal hormonal levels were achieved along with gross total tumor removal. Surgical complications were evaluated, and postoperative follow-up with laboratory and imaging studies were performed.
\end{abstract}

Results: 78 patients were operated by trans nasal route in our hospital between January 2014-June 2021. Of these 78 pituitary tumors, 22 were growth hormone secreting adenoma. The study population consisted of 22 people, 11 men and 11 women, and the average age of the population was calculated as 60.45 years \pm 18.4 . Statistical analysis showed that the difference between the pre-operative and post-operative somamedine and growth hormone level was statistically significant

Conclusions: Microscopic Trans-Sphenoidal Surgery for Acromegalic patients is a minimally invasive, safe, and efficacious choice

Key words: Adenoma, Surgery, Trans-sphenoidal, Pituitary.

Suggested Citation: Ozdemir B, Batcik O E. Trans-Sphenoidal Surgery for "Growth Hormone-secreting adenoma; Revisiting Surgical Outcome. Mid Blac Sea Journal of Health Sci, 2021; 7(2):205-211.

Address for correspondence/reprints:

Osman Ersegun Batçık

Telephone number: +90 (505) 5908686

E-mail: osmanersegun@gmail.com 


\section{Introduction}

Pituitary gland locates in an area of complex anatomical structures, but it holds a very important physiological role to maintain all body function (1). The most common type of pituitary tumor is a benign pituitary adenoma, which occurs in the sellar and suprasellar regions (2). These tumors are referred to as those atypical tumors, which are not only benign slowly developing, but also show development of the pituitary gland (3). 12\% of all cerebral tumors are pituitary adenoma (PA)(4). It is the third primary brain tumor to be common. (5). While most of them are not symptomatic, they may cause a wide range of signs which depend on their hormone function (3). PA's primary clinical signs include endocrinologic syndrome characteristic, whether because of hormone hypersecretion or deficiencies, compressive symptoms or unusually acute or subacute pituitary apoplexy (6). PA can be of various subtypes depending on the source cell or the corresponding hormones (non-functioning PA, prolactinoma, somatotropinoma, corticotropinoma, thyrotropinoma, and gonadotropinoma) (7). Functioning PA is relatively more morbid and mortal due to the associated hormone hypersecretion syndromes (7). Functional PA diagnosis is determined using biochemical hormone hypersecretion confirmation and imaging pituitary lesion (7). The treatment of functioning pituitary tumors consists of one or more of the following 3 modalities: surgery, radiation therapy (RT) and medical therapy (7). In the late 1960s, pituitary surgery evolved from a craniotomy approach toward less invasive approaches, in particular microscopic and endoscopic $(8,9)$. All tumor tissue (i.e. gross total resection) should be removed, pressures should be alleviated and the risk of relapse reduced (10). Currently, surgical procedure can be carried out by two different techniques: microscopic or endoscopic (7). The trans-sphenoidal route (both the sublabials and cross-nasals)- with the advent of the operative microscope in the 1960s became the gold standard for approaching the sellar area lesions (11). The first-line treatment of most types of tumors is transsphenoidal surgical resections, except for prolactinomas, in which the treatment is preferred with dopamine agonists (7), because these adenomas' surgical approaches have higher risk of complications (4). Other options for managing PA are RT and medical therapy (7). Growth hormone (GH)secreting PA is an insidious disease with an estimated incidence of 30 to 50 cases $/ 1$ million population annually (12). Acromegaly is caused by an excess of $\mathrm{GH}$, most commonly caused by a somatotroph PA, and is associated with significant metabolic changes that have a negative impact on quality of life (13). Uncontrolled acromegaly patients experience a lower life expectancy of 10-15 years and suffer from multimorbidity (14).

\section{Methods}

Recep Tayyip Erdogan University Non-Invasive Clinical Research Ethical Committee approved the study. Preoperative and postoperative medical records of the patients were evaluated. Data collection involved examination of the clinical and surgical notes, including indications for surgery, histopathology, pituitary magnetic resonance imaging (MRI) findings, cerebrospinal fluid (CSF) leak grade, complications. Hormonal and visual status were also evaluated. According to preoperative hormonal and clinical features, tumors were classified into clinically 'functioning' and 'nonfunctioning'. Pre- and post-operative somatomedin and GH levels were compared. The postoperative results were evaluated in terms of the control of hormone hypersecretion and safety of surgical procedure.

\section{Neuroimaging evaluation}

Traditional MRI sequences, such as contrastenhanced (CE), T1 weighted image (WI), and T2WI, are commonly used to assess adenoma characteristics such as invasion and size (15). All patients in this study were evaluated with a $1.5 \mathrm{~T}$ magnetic resonance imaging (MRI) unit before surgery, using T1- and T2weighted spin echo before and after the addition of gadolinium-based contrast. This radiological model was used to assess the configuration and size of tumors, as well as their extensions into the suprasellar, infrasellar, or parasellar region. Preoperative MRI are presented in Figure 1. 


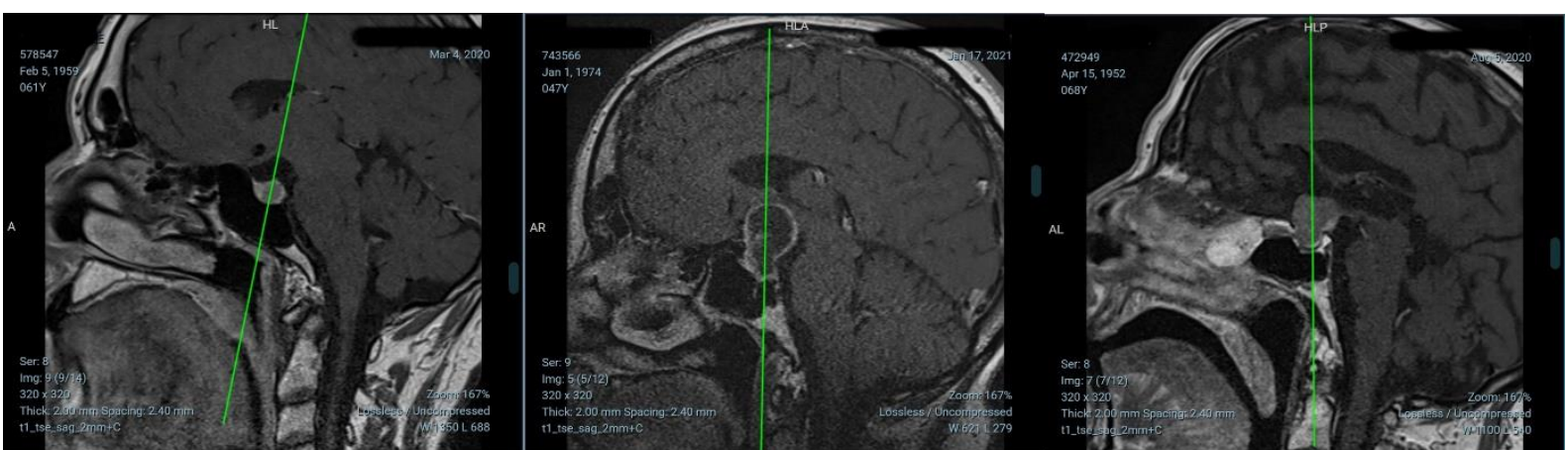

Figure 1. Preoperative MRI of patients
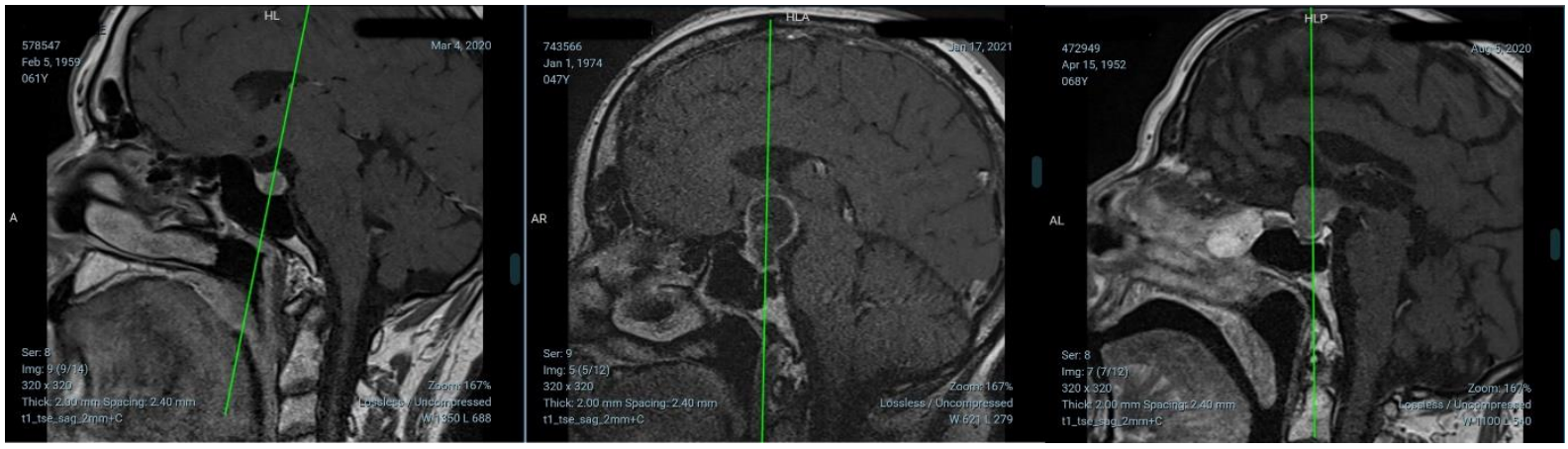

Figure 2. Postoperative MRI of patients

\section{Surgical Procedure}

The transsphenoidal approach was performed using an endonasal transseptal microsurgical technique. The patient was positioned semi-sitting, with the head rotated $15^{\circ}$ to the right and tilted to the left. The sphenoid sinus is about $20 \mathrm{~mm}$ deep, $70-90$ $\mathrm{mm}$ deep to the nasal spine, and has a $30^{\circ}$ angle to the nasal cavity floor (9). Irrigation was used to control venous bleeding after removing the sphenoid sinus mucosa. The sellar floor was removed sufficiently, and the dura was opened. The tumor was resected. The arachnoid layer has been closely watched. Hemostasis was meticulously maintained in the tumor cavity, and hemostatic agents such as a gelatin sponge (Spongostan; Ferrosan, Seborg, Denmark) were used, when necessary, in the cavity. The dura was opened in a cruciate fashion from laterally to medially to prevent inadvertent injury to the sinuses. The nasal bony septum, sphenoidal rostral bone fragments, cellulose, and an autologous abdominal adipose graft were used to reconstruct the sella turcica floor. As in Villar-Taibo et al's study, surgical complications were classified as intraoperative (during surgery), immediate postoperative (within the first week after surgery), and late postoperative (within the first month after surgery) (6).

\section{Follow-up}

Follow-up monitoring included postoperative MRI, endocrinological and neurological evaluations, performed at 3 months after surgery as in the study of Asioli et al. (16). The patients were followed for a period of 61 months. MRI scans were obtained 3 and 6 months after surgery. Postoperative MRI are presented in Figure 2.

\section{Statistical analysis}

SPSS 20.0 for Windows (SPSS, Inc, Chicago, Illinois, USA) was used to perform statistical calculations. When describing sociodemographic variables, frequencies, means, standard deviations and median were used. Normality for continuous variables was tested by using Shapiro-Wilk test. Wilcoxon sign rank test was performed because preoperative and postoperative somatomedin and GH level were not normally distributed. Significance was set at $\mathrm{p}<0.05$.

\section{Results}

78 patients were operated by trans nasal route in our hospital between January 2014-June 2021 in the Neurosurgery Department of Recep Tayyip Erdogan University University Faculty of Medicine. All operations have been conducted in collaboration with 2 neurosurgeons. Of these $78 \mathrm{PA}, 22$ were GH secreting adenoma. The tumors were classified as microadenomas (0-10 mm; $\mathrm{n}: 2)$, macroadenomas (10-29 mm:15), large adenomas ( $\geq 30 \mathrm{mmn}: 4)$, and giant adenomas ( $\geq 40 \mathrm{mmn}: 1)$ based on their diameter. Acromegaly was present in 22 cases. There were 11 
women and 11 men in this group, with a mean age of 60,45 years \pm 18.4 . All 22 patients underwent a single surgical procedure. The surgical goal was gross total resection and hormonal cure, which have been achieved in the majority of patients. Median hospitalization duration was 4 days. Demographic and operative data are given in table 1 . Early period CSF fistulas were observed in 3 patients. Diabetes insipidus occurred in 3 patients. Reoperation for recurrent adenoma was required only in 3 patients.

Table 1. Demographic and Operative Data

\begin{tabular}{ll}
\hline Age (year, mean \pm SD) & $60.45 \pm 18.4$ \\
\hline Gender $($ female/male) N & $11 / 11$ \\
\hline BMI (kg/m2, mean \pm SD) & $26.49 \pm 4.75$ \\
\hline Tumor classification & $\mathbf{N}$ \\
\hline Microadenoma & 2 \\
\hline Macroadenoma & 15 \\
\hline Large Adenoma & 4 \\
\hline Giant Adenoma & 1 \\
\hline Operation duration (minute, mean \pm SD) & $98.12 \pm 22.35$ \\
\hline Hospitalization duration (day, median) & $4 \pm 1,37$ \\
\hline BMI: Body Mass Index &
\end{tabular}

\section{Postoperative assessments}

Every single patient was closely followed up for the development of complications. At the 8th week and 3rd month, after surgery, routine follow-up was performed in the outpatient clinic. A full hormonal test was performed to assess pituitary function in depth. An MRI was routinely performed at 6 months to assess a tumor remnant as well as to establish a baseline measurement for future recurrence assessments. There was no death in this series. The mean pre- and post-operative 8 th week somatomedin levels were $342,19 \mathrm{ng} / \mathrm{mL}$ and $144,77 \mathrm{ng} / \mathrm{mL}$ respectively. The difference of pre-operative and post-operative level of somatomedin was statistically significant $(\mathrm{P}=0.002,<0.01)$. Mean pre-operative growth hormone level was decreased from $2,6 \mathrm{ng} / \mathrm{mL}$ to $0.7 \mathrm{ng} / \mathrm{mL}$. The difference was also statistically significant $(\mathrm{p}=0.003,<0.01)$ (Table 2$)$.

Table 2. Pre and postoperative somatomedine and growth hormone levels

\begin{tabular}{llll}
\hline $\begin{array}{l}\text { Hormonal } \\
\text { parameters }\end{array}$ & $\begin{array}{l}\text { Preoperative } \\
(\text { mean } \pm \text { SD) }\end{array}$ & $\begin{array}{l}\text { Postoperative } \\
(\text { mean } \pm \text { SD) }\end{array}$ & $\mathrm{p}$ \\
\hline $\begin{array}{l}\text { Somatomedin, } \\
\text { ng/mL }\end{array}$ & $342.19 \pm 303.96$ & $144.77 \pm 93.37$ & $0.002^{* *}$ \\
\hline $\begin{array}{l}\text { Growth hormon, } \\
\text { ng/mL }\end{array}$ & $2.6 \pm 3.99$ & $0.75 \pm 1.23$ & $0.003^{* *}$ \\
\hline
\end{tabular}

Wilcoxon sign rank test, ${ }^{* *} \mathrm{p}<0.01$

\section{Discussion}

Acromegaly is the result of unrestricted GH secretion, which is a serious medical disorder. (17). Although typically benign under a histological point of view, PAs can exhibit an aggressive clinical and radiological behavior, characterized by quick growth, along with resistance or early recurrence, with the gross invasion of the surrounding tissues after treatment. (16). As the pituitary adenoma is the most common cause of acromegaly pituitary MRI may be helpful in the diagnosis of acromegaly. Enlarged pituitary gland with gadolinium uptake and extend of adenoma to the suprasellar region are observed on MRI. Findings on MRI for spine are hypertrophy of spinal ligaments and cartilaginous structures and osteoarthritis. In addition to these findings, joints MRI shows ligamentous and cartilaginous hypertrophy and crystal deposition (18). The longterm effects of chronic $\mathrm{GH}$ excess on metabolism and the cardiovascular system are negative, and include diabetes mellitus, arterial hypertension, heart disease, and an increased risk of cancer (17). In acromegaly, somatostatin receptor ligands (octreotide, lanreotide, pasireotide), dopamine agonists (cabergoline) and GH receptor antagonist (pegvisomant) are used for medical treatment (19). The surgical treatment of these adenoma is aimed at restoring $\mathrm{GH}$ levels as soon as possible (13), we noted a statistically significant decrease of GH levels in this study.

Pituitary adenomas are tumors of extraarachnoidal origin, so usually grow outside the confines of CSF (20). As the tumor lies in close relationship to the diaphragm sellae and subarachnoid space, there is always a risk of iatrogenic arachnoid breach (20). As a result, CSF leak is a common complication of this surgery (20) among several transsphenoidal chirurgical complications. Apart from CSF leak, transient diabetes insipidus, permanent diabetes insipidus, minor nasal bleeding, and hyposmia can be seen after microsurgical surgery (21). The optimal treatment for GH secreting PA is trans-sphenoidal pituitary surgery (22). The first treatment option in acromegaly is surgical removal of the adenoma. Patients with severe mass effects, such as vision loss or double vision, require immediate surgical treatment. Medical treatment can be applied before surgical treatment in patients at risk of anesthesia such as cardiomyopathy, uncontrolled diabetes mellitus, severe hypertension and sleep apnea. Following the application of medical treatment for 3-6 months, surgical intervention can be performed for patients whose anesthesia and surgical risks are reduced. After successful adenoma resection, clinical improvement begins within days (19). The anatomy of the pituitary fossa's roof varies greatly (23). A "barrier" of three anatomical structures exists between the adenoma and the CSF (23). This tripartite structure progressing from the cephalad to the cauda consists of arachnoid, dura 
mater (ie sellar diaphragm) and pituitary gland tissue. Of these three elements, only the arachnoid is found in every human (23). In the literature, CSF leaks have been reported varying from $0.5 \%$ to $10.3 \%$ (20). We had a total of $3(13,6 \%)$ cases with postoperative CSF leak. Three cases needed re-exploration. Potential morbidities following CSF leaks include meningitis, prolonged hospitalization, tension pneumocephalus and additional operations (24).

\section{Outcomes of Surgery}

Surgical procedure outcomes are frequently reported in the literature in a clinician-centered manner (25). Traditional surgical outcome studies concentrate on efficacy measures like remission rates and gross total resection (25). An important aim of treatment of patient with PA is to improve or preserve health-related quality of life (26). The recovery of pituitary function is much less than that of vision (27). Re-emergence of symptoms of acromegaly with reincreased GH and IGF-1 levels is defined as recurrence after surgical control (28). According to the literature, the recurrence rate ranges from $0 \%$ to $31 \%$ (28). In this study, the patients were followed for $6 \pm 1$ months. Recurrence was observed in 3 patients. Although we are aware that the postoperative timing of MRI following PA surgery is still controversial, MRI scans of patients were obtained at the third and sixth months after surgery (29). Follow-up of asymptomatic residual tumor should be following up (29). Early evaluation is frequently difficult in the setting of acute postoperative changes such as hemorrhage, packing, and, in some cases, undescended residual tumor (29). The rationale for early postoperative imaging is to give surgeons a chance to intervene earlier for residual tumor (29). Important predictors of surgical outcome of $\mathrm{GH}$ secreting PA are tumor size, invasiveness, duration of acromegaly, and preoperative GH levels (13). GHsecreting PA, the predominant cause of acromegaly, is associated with a standardized mortality rate of $0.72-1.13(28)$. No mortality was seen in this series.

\section{Conclusion}

This study indicates that patients undergoing surgery for acromegaly can have excellent outcomes. Low complication rates and high resection rates were noted in the present study. The length of stay in hospital was not long. Although it is considered a relatively safe procedure in transsphenoidal pituitary surgery, postoperative complications should be expected. Knowing about these complications is the first step in preventing them (1). Timely diagnosis and effective treatment to control hormone hypersecretion and relieve mass effects along with replacement of deficient hormones are crucial to reduce these associated health risks (7), because PA invasion of local structures on MRI is associated with postoperative outcomes following surgical resection (15). We recommend the transsphenoidal surgery for GH secreting PA as a safe and effective approach.

Ethics Committee Approval: This study was conducted with the approval of the ethics committee of Recep Tayyip Erdogan University Faculty of Medicine, Non-Invasive Clinical Research Ethics Committee. (Ethics Committee date and Decision no: 26.04.2021 2021/75)

Peer-review: Externally peer-reviewed.

Author Contributions: Concept: B.O. Design: B.O. Literature Search: B.O, O. E. B.; Data Collection and Processing: B.O, O. E. B.; Analysis or Interpretation: B.O, O. E. B.; Writing: B.O, O. E. B. Conflict of Interest: The authors do not declare any conflict of interest.

Financial Disclosure: No financial support was received for this study.

\section{References}

1. Koirala S, Shrestha BK, Lohani S, Bishokarma S, Devkota UP. Postoperative Complications of Transsphenoidal Pituitary Adenectomy: A Single Institution Based Experience. Kathmandu Univ Med J (KUMJ). 2019;17(66):123-5.

2. Van Gerven L, Qian Z, Starovoyt A, Jorissen M, Meulemans J, van Loon J, et al. Endoscopic, Endonasal Transsphenoidal Surgery for Tumors of the Sellar and Suprasellar Region: A Monocentric Historical Cohort Study of 369 Patients. Front Oncol. 2021;11:643550.

3. Li J, Ding W, Huang Z, Xie B, Li Z-Y. Comparison of Short-Term Outcomes Between Endoscopic and Microscopic Trans-Sphenoidal Surgery for the Treatment of Pituitary Adenoma. J Craniofac Surg. 2019;30(8):2421-4.

4. Müslüman AM, Cansever T, Yilmaz A, Kanat A, Oba E, Çavuşoğlu H, et al. Surgical results of large and giant pituitary adenomas with special consideration of ophthalmologic outcomes. World Neurosurg. 2011;76(1-2).

5. Thakur JD, Corlin A, Mallari RJ, Huang W, Eisenberg A, Sivakumar W, et al. Pituitary adenomas in older adults ( $\geq 65$ years): 90-day outcomes and readmissions: a 10-year endoscopic endonasal surgical experience. Pituitary. 2021;24(1):14-26. 
6. Villar-Taibo R, Díaz-Ortega C, Sifontes-Dubon M, Fernández-Pombo A, Serramito-García R, Martínez-Capoccioni G, et al. Pituitary surgery in elderly patients: a safe and effective procedure. Endocrine. 2021;72(3):814-22.

7. Thakkar K, Sarathi V, Shah NS. Current Status of Diagnosis and Management for Functioning Pituitary Tumors: Part I. Neurol India. 2020;68:13-9.

8. Karamouzis I, Caputo M, Mele C, Nuzzo A, Zavattaro M, Car P, et al. Transsphenoidal surgery for pituitary adenomas: early results from a single center. Hormones (Athens). 2018;17(4):551-6.

9. Jain AK, Gupta AK, Pathak A, Bhansali A, Bapuraj JR. Excision of pituitary adenomas: randomized comparison of surgical modalities. $\mathrm{Br}$ J Neurosurg. 2007;21(4):328-31.

10. Møller MW, Andersen MS, Glintborg D, Pedersen CB, Halle B, Kristensen BW, et al. Endoscopic vs. microscopic transsphenoidal pituitary surgery: a single centre study. Sci Rep. 2020;10(1):21942.

11. Mattogno PP, Mangiola A, Lofrese G, Vigo V, Anile C. Efficacy of Microsurgical Sublabial Approach (MSA) Versus Endoscopic Endonasal Approach (EEA) for the Treatment of Pituitary Adenomas Based on Radiological and Hormonal Outcome. Acta Neurochir Suppl. 2017;124:1016.

12. Shen M, Tang Y, Shou X, Wang M, Zhang Q, Qiao N, et al. Surgical Results and Predictors of Initial and Delayed Remission for Growth Hormone-Secreting Pituitary Adenomas Using the 2010 Consensus Criteria in 162 Patients from a Single Center. World Neurosurg. 2018; 27;S1878-8750(18)32738-4. 10.1016/j.wneu.2018.11.179.

13. Goyal-Honavar A, Sarkar S, Asha HS, Kapoor N, Thomas R, Balakrishnan R, et al. Impact of experience on outcomes following endoscopic transsphenoidal surgery for acromegaly. World Neurosurg. 2021; 151:e1007-e1015. doi: 10.1016/j.wneu.2021.05.030.

14. Coopmans EC, Postma MR, Wolters TLC, van Meyel SWF, Netea-Maier R, van Beek AP, et al. Predictors for Remission after Transsphenoidal Surgery in Acromegaly: A Dutch Multicenter Study. J Clin Endocrinol Metab. 2021;106(6):1783-92.

15. Braileanu M, Hu R, Hoch MJ, Mullins ME, Ioachimescu AG, Oyesiku NM, et al. Preoperative MRI predictors of hormonal remission status post pituitary adenoma resection. Clin Imaging. 2019;55:29-34.
16. Asioli S, Righi A, Iommi M, Baldovini C, Ambrosi F, Guaraldi F, et al. Validation of a clinicopathological score for the prediction of post-surgical evolution of pituitary adenoma: retrospective analysis on 566 patients from a tertiary care centre. Eur J Endocrinol. 2019;180(2):127-34.

17. Jamjoom ZA, Al-Maatouq M, Jamjoom AH, Malabarey T, Al-Rubeaan K, Ur-Rahman N, et al. Growth hormone secreting pituitary adenoma: Clinical aspects and surgical outcome. Ann Saudi Med. 1995;15(2):178-82.

18. Famini P, Maya MM, Melmed S (2011). "Pituitary magnetic resonance imaging for sellar and parasellar masses: ten-year experience in 2598 patients". J Clin Endocrinol Metab. 2011: 96 (6): 1633-41.

19. Türkiye Endokrinoloji ve Metabolizma Derneği 2018 Somatotrof Adenom. Hipofiz Hastalıkları Tanı, Tedavi ve İzlem K1lavuzu. 2018:29-37.

20. Goyal P, Gupta A, Srivastava S, Modi S. Avoiding Complications in Endoscopic TransSphenoidal Surgery for Pituitary Adenoma: A Beginner's Perspective. Asian J Neurosurg. 2020;15(4):899-907.

21. Cıkla U, Binatlı AÖ, Demirçivi Özer F, Çiftçi E. Comparison of endoscopic and microsurgical techniques for transsphenoidal pituitary surgery. J Nervous Sys Surgery. 2010; 3(2):61-5.

22. Wang Q, Guo X, Gao L, Wang Z, Deng K, Lian W, et al. Surgical Outcome of Growth HormoneSecreting Pituitary Adenoma with Empty Sella Using a New Classification. World Neurosurg. 2017;105:651-8.

23. Campero A, Villalonga JF, Basso A. Anatomical Risk Factors for Intraoperative Cerebrospinal Fluid Leaks During Transsphenoidal Surgery for Pituitary Adenomas. World Neurosurg. 2019; 1878-8750(18)32917-6. doi: 10.1016/j.wneu.2018.12.094

24. Shiley SG, Limonadi F, Delashaw JB, Barnwell SL, Andersen PE, Hwang PH, et al. Incidence, etiology, and management of cerebrospinal fluid leaks following trans-sphenoidal surgery. Laryngoscope. 2003 Aug;113(8):1283-8.

25. de Vries F, Lobatto DJ, Verstegen MJT, Schutte PJ, Notting IC, Kruit MC, et al. Outcome Squares integrating efficacy and safety, as applied to functioning pituitary adenoma surgery. J Clin Endocrinol Metab. 2021;106(9):e3300-e3311 
26. Sommerfelt H, Sagberg LM, Solheim O. Impact of transsphenoidal surgery for pituitary adenomas on overall health-related quality of life: a longitudinal cohort study. $\mathrm{Br} \mathrm{J}$ Neurosurg. 2019;33(6):635-40.

27. Baldia M, Rajaratnam S, Rajshekhar V. Postoperative Hormonal Outcomes in Patients with Large and Giant Non-functioning Pituitary Adenomas. Neurol India. 2020;68:106-12.

28. Shen M, Chen Z, Shou X, He W, Qiao N, Ma Z, et al. 2010 versus the 2000 consensus criteria in patients with normalised insulin-like growth factor 1 after transsphenoidal surgery has high predictive values for long-term recurrence-free survival in acromegaly. J Neuroendocrinol. 2021;33(5):e12958.

29. Kunigelis KE, Arnone G, Chatain G, Hoffman J, Chatain O, Coulter I, et al. Defining the timing and role of acute postoperative imaging in pituitary adenoma surgery: clinical study. Acta Neurochir (Wien). 2020;162(10):2353-60. 